\title{
MYC Up-regulation Is a Useful Biomarker for Preoperative Neoadjuvant Chemotherapy Combined With Anti-EGFR in Liver Metastasis from Colorectal Cancer
}

\author{
TAKAZUMI KATO ${ }^{1}$, NOBUHISA MATSUHASHI ${ }^{1 *}$, HIROYUKI TOMITA ${ }^{2 *}$, TAKAO TAKAHASHI ${ }^{1}$, \\ YOSHINORI IWATA ${ }^{1}$, MASAHIRO FUKADA ${ }^{1}$, ITARU YASUFUKU ${ }^{1}$, TOMONARI SUETSUGU ${ }^{1}$, \\ TAKEHARU IMAI ${ }^{1}$, RYUTARO MORI $^{1}$, HISASHI IMAI ${ }^{1}$, YOSHIHIRO TANAKA ${ }^{1}$, \\ NAOKI OKUMURA ${ }^{1}$, AKIRA HARA ${ }^{2}$ and KAZUHIRO YOSHIDA ${ }^{1}$ \\ ${ }^{1}$ Department of Surgical Oncology, Gifu University Graduate School of Medicine, Gifu, Japan; \\ ${ }^{2}$ Department of Tumor Pathology, Gifu University Graduate School of Medicine, Gifu, Japan
}

\begin{abstract}
Background/Aim: At present, there are no biomarkers to predict the effects of molecular targeted drugs in patients with CRC with liver metastasis. Thus, we performed this study to explore potential biomarkers for these patients. Materials and Methods: We obtained cancer tissue specimens from liver metastasis-bearing CRC patients who received the following preoperative neoadjuvant chemotherapies with molecular targeted drugs: $i)$ no therapy (n=3), ii) 5-FU+oxaliplatin+anti-EGFR $(n=3)$, iii) and 5$F U+$ oxaliplatin+anti-VEGF $(n=3)$. Results: We investigated the RNA expression of 84 genes related to cancer drug resistance using an RT-PCR array. The MYC gene was the only gene that was significantly up-regulated in CRC tissue specimens from anti-EGFR group in comparison to the anti$V E G F$ group. Conclusion: MYC up-regulation in the primary CRC tissues may be a potentially useful biomarker for selecting anti-EGFR combination therapy in neoadjuvant chemotherapy for CRC with liver metastasis.
\end{abstract}

There is marked variation in the incidence and mortality rates of colorectal cancer (CRC) worldwide. Around the world, CRC is the second and third most commonly diagnosed cancer in females and males, respectively. The

This article is freely accessible online.

*These Authors contributed equally to this work.

Correspondence to: Nobuhisa Matsuhashi, Department of Surgical Oncology, Gifu University School of Medicine, Yanagido, Gifu City, 501-1194, Japan. Tel: +81 582306233, Fax: +81 582301074, e-mail: nobuhisa517@hotmail.com

Key Words: MYC gene, molecular target drug, colorectal cancer, liver, metastasis.
World Health Organization GLOBOCAN database indicates that there were 1.8 million new cases and almost 861,000 deaths from $\mathrm{CRC}$ in 2018. The rates in males are considerably higher than those in females. The regional incidence of CRC globally varies by over 10-fold, with Australia and New Zealand, Europe, and North America having the highest incidence rates (1).

In Japan, the incidence and mortality of CRC cancer have increased markedly. According to the Foundation Cancer Research Promotion Foundation 'Cancer Statistics', the number of CRC deaths among females is first among all malignant plasms. In males, it is the third most common, following lung and gastric cancer (2). The rate of 5-year survival in patients with Stage I-III CRC who can undergo curative resection has reached nearly $80 \%$; however, survival of patients with Stage IV CRC, which accounts for approximately $18 \%$ of all cases, is only $13 \%$ and is considered unsatisfactory. Liver metastasis occurs in almost $60 \%$ of patients with Stage IV CRC. In contrast, recurrence in the liver is only observed in $9-13 \%$ of patients after curative resection of the primary CRC (3). To improve the prognosis of patients with $\mathrm{CRC}$, the treatment outcomes of patients with liver metastasis must also be improved.

Molecular targeted therapy is gaining ground in personalized medical treatment for patients with colorectal metastasis (CLM). For these patients, two options, currently available in routine clinical practice, include anti-epidermal growth factor receptor (anti-EGFR) antibodies and antivascular endothelial growth factor (anti-VEGF) antibodies (4, 5). Anti-EGFR antibodies include the chimeric monoclonal antibody cetuximab and the fully human monoclonal antibody panitumumab. Both antibodies inhibit downstream signaling pathways of EGFR that result in the inhibition of cellular proliferation and angiogenesis (6). Bevacizumab, a humanized monoclonal anti-VEGF antibody, binds to VEGF 
Table I. Patient characteristics.

\begin{tabular}{|c|c|c|c|c|c|c|c|c|c|c|}
\hline & Age & Gender & $\begin{array}{l}\text { Primary } \\
\text { location }\end{array}$ & Histology & $\begin{array}{l}\text { TNM } \\
\text { stage }\end{array}$ & $\mathrm{H}$ & $\mathrm{T}$ & $\mathrm{N}$ & M & Grade \\
\hline \multicolumn{11}{|c|}{ A: Surgery alone } \\
\hline 1 & 62 & F & $\mathrm{T}$ & tub1 & I & $\mathrm{H} 1$ & $\mathrm{~T} 2$ & No & M0 & - \\
\hline 2 & 50 & F & RS & tub2 & I & $\mathrm{H} 1$ & $\mathrm{~T} 2$ & No & M0 & - \\
\hline 3 & 80 & F & $\mathrm{S}$ & tub1 & $\mathrm{IIb}$ & $\mathrm{H} 1$ & $\mathrm{~T} 4 \mathrm{a}$ & No & M0 & - \\
\hline \multicolumn{11}{|c|}{ B: L-OHP+EGFR } \\
\hline 1 & 58 & F & RS & tub2 & IIIB & $\mathrm{H} 2$ & $\mathrm{~T} 4 \mathrm{a}$ & $\mathrm{N} 1 \mathrm{~b}$ & M0 & $1 \mathrm{a}$ \\
\hline 2 & 54 & F & $\mathrm{Ra}$ & tub2 & IVa & $\mathrm{H} 1$ & $\mathrm{~T} 3$ & $\mathrm{~N} 1 \mathrm{~b}$ & M1 & 3 \\
\hline 3 & 49 & $\mathrm{~F}$ & $\mathrm{~S}$ & tub1 & IVa & $\mathrm{H} 2$ & $\mathrm{~T} 2$ & No & M1 & $1 \mathrm{~b}$ \\
\hline \multicolumn{11}{|c|}{$\mathrm{C}: \mathrm{L}-\mathrm{OHP}+\mathrm{BV}$} \\
\hline 1 & 63 & $\mathrm{~F}$ & A & tub2 & $\mathrm{IVb}$ & $\mathrm{H} 2$ & $\mathrm{~T} 4 \mathrm{a}$ & $\mathrm{N} 2 \mathrm{~b}$ & M1b & 3 \\
\hline 2 & 68 & M & $\mathrm{T}$ & muc & IVa & $\mathrm{H} 1$ & $\mathrm{~T} 4 \mathrm{a}$ & $\mathrm{N} 2 \mathrm{~b}$ & M1 & $1 \mathrm{a}$ \\
\hline 3 & 64 & M & RS & tub2 & IVa & $\mathrm{H} 2$ & $\mathrm{~T} 3$ & No & M1 & 3 \\
\hline
\end{tabular}

M: Male; F: female. Primary location: A: ascending colon; T: transverse colon; S: sigmoid colon; RS: recto-sigmoid; Ra: above rectum. Tub: tubular adenocarcinoma; muc: mucinous adenocarcinoma. TNM staging system: T: tumor, N: node, M: metastasis. L-OHP: oxaliplatin; EGFR: epidermal growth factor receptor; VEGF: vascular endothelial growth factor.

and inhibits it from binding to its functional receptor; this prevents tumor vessel growth and neovascularization and decreases the permeability of the surviving vasculature (7).

The combination of cytotoxic chemotherapy with antiVEGF antibody or anti-EGFR antibodies plus standard chemotherapy results in greater efficacy compared to cytotoxic chemotherapy alone $(8,9)$. However, as this combination regimen of two-antibodies is commonly used in first- or second-line therapy, it remains controversial which of the two inhibitors provides superior efficacy for patients with all-RAS wild-type CLM in combination with chemotherapy (10). In the present study, we used an RT2 Profiler PCR array to evaluate available clinical samples (CRC primary tumor and liver tumor after chemotherapy with a targeted monoclonal antibody drug) in combination with a VEGF inhibitor in comparison to EGFR inhibitors in patients with all-RAS wild-type CLM.

\section{Materials and Methods}

Clinical samples were obtained from CRC patients who underwent treatment at Gifu University (Gifu, Japan) from January 2010 to January 2016. Nine sets of naïve primary tumors and remaining metastatic liver tumors (Table I) were used for this analysis: A) tumors not treated with chemotherapy (3 sets) with metastatic liver tumors ( 3 sets), B) tumors not treated with chemotherapy (3 sets) with metastatic liver tumors after chemotherapy regimens, such as folinic acid, fluorouracil, and oxaliplatin (FOLFOX), containing antiEGFR therapy ( 3 sets), and C) tumors not treated with chemotherapy (3 sets) with metastatic liver tumors after chemotherapy regimens (e.g., FOLFOX) containing anti-VEGF therapy (3 sets).

This study was approved by the Central Ethics Committee of Gifu University. We obtained written informed consent from all patients enrolled in this study. The study protocol conformed to the ethical guidelines of the 1975 Declaration of Helsinki and the guidelines of the regional ethical committees of Zurich and Basel,
Switzerland, and was approved by the Institutional Review Board of the Gifu University Graduate School of Medicine (Approval number: 28-508; March 23, 2017).

RNA extraction and the PCR array analysis. The expression levels of 84 aging-related genes were determined using the Human Cancer Drug Resistance RT2 Profiler PCR array (Cat\# PAHS-004Z) (Qiagen, Frederick, MD, USA). Total RNA was extracted from frozen tumor samples via the RNeasy Mini Kit (Qiagen, TX, USA). Coding DNA (cDNA) was synthesized from $1 \mu \mathrm{g}$ total RNA using the RT2 PCR Array First Strand kit (Qiagen). Real-time PCR was performed in triplicate in 96-well plates using RT2 SYBR Green qPCR Master Mix (Qiagen) and StepOne Plus Real-Time PCR System (Applied Biosystems, Foster City, CA, USA). All genes and data are listed in Table II. The results were normalized using the housekeeping gene $A C T B$ and analyzed by the comparative $\mathrm{Ct}$ method.

RECIST guidelines (version 1.1). Presently, the best and most reproducible method with which to measure lesions when assessing a treatment response is computed tomography $(\mathrm{CT})$. The RECIST guidelines define lesion measurability on $\mathrm{CT}$ scans based on a slice thickness of $\leq 5 \mathrm{~mm}$. If the slice thickness is $>5 \mathrm{~mm}$, the minimum size of the measurable lesion must be at least twice the slice thickness.

Evaluation of target lesions. Target lesions were evaluated as described below.

Complete Response (CR) indicates the disappearance of all target lesions. Any pathological lymph nodes (target or non-target) must have a reduction in their short axis to $<10 \mathrm{~mm}$.

Partial response (PR) indicates at least a $30 \%$ decrease in the sum of the diameters of the target lesions in comparison to the baseline sum diameters.

Progressive disease (PD) indicates at least a $20 \%$ increase in the sum of the diameters of the target lesions in comparison to the smallest sum in the study (including the baseline sum if that is the smallest one in the study). In addition to the $20 \%$ relative increase, the sum must also show an absolute increase of at least $5 \mathrm{~mm}$. The appearance of one or more new lesions is also considered progression. 
Table II. All 84 aging-related genes from the Human Cancer Drug Resistance RT2 Profiler PCR array.

\begin{tabular}{|c|c|c|c|c|c|c|c|c|c|c|c|c|}
\hline Lay out & 01 & 02 & 03 & 04 & 05 & 06 & 07 & 08 & 09 & 10 & 11 & 12 \\
\hline A & ABCB1 & $\mathrm{ABCC} 1$ & $\mathrm{ABCC} 2$ & $\mathrm{ABCC} 3$ & ABCC5 & ABCG2 & AHR & AP1S1 & APC & AR & ARNT & ATM \\
\hline B & BAX & BCL2 & BCL2L1 & BLMH & BRCA1 & BACR2 & CCND1 & CCNE1 & CDK2 & CDK4 & CDKN1A & CDKN18 \\
\hline $\mathrm{C}$ & CDKN2A & CDKN2D & CLPM1L & CYP1A1 & CYP1A2 & CYP286 & CYP2C19 & CYP2C8 & CYP2C9 & CYP2D6 & CYP2E1 & CYP3A4 \\
\hline D & CYP3A5 & DHFR & EGFR & ELK1 & EPHX1 & ERBB2 & ERBB3 & ERBB4 & ERCC3 & ESR1 & ESR2 & FGF2 \\
\hline $\mathrm{E}$ & FOS & GSK3A & GSTP1 & HIF1A & IGF1R & IGF2R & MET & MSH2 & MVP & MYC & NAT2 & NFKB1 \\
\hline $\mathrm{F}$ & NFKB2 & NFKBIB & NFKBIE & PPARA & PPARD & PPARG & RARA & RARB & RARG & RB1 & RELB & RXRA \\
\hline G & RXRB & SOD1 & SULT1E1 & TNFRSF11A & TOP1 & TOP2A & TOP2B & TP53 & TPMT & UGCG & XPA & XPC \\
\hline
\end{tabular}

A

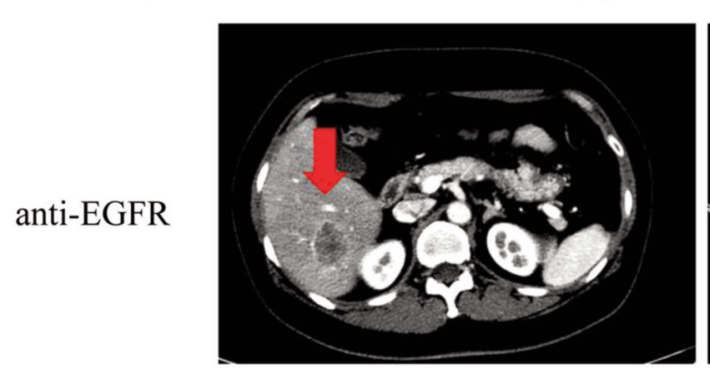

B

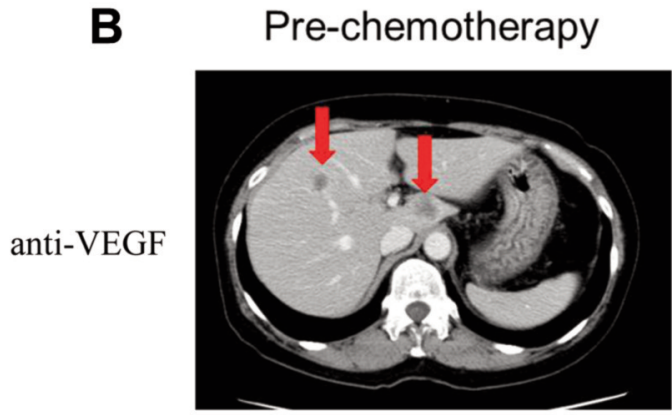

Post-chemotherapy

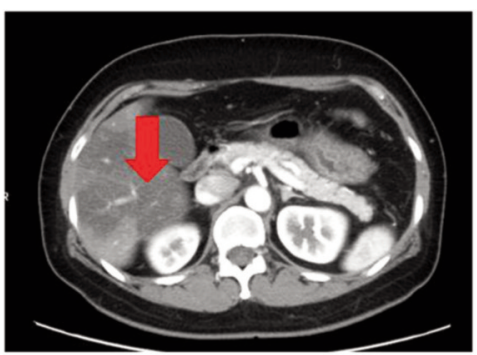

Post-chemotherapy

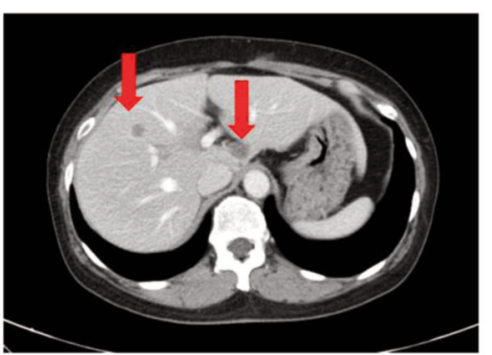

Figure 1. Computed tomography imaging. Computed tomography images showing the response of colorectal cancer liver metastasis to chemotherapy. A) Liver metastasis (arrow) before (left side) and after (right side) EGFR chemotherapy (B group: case 3). B) Liver metastasis (arrows) before (left side) and after (right side) VEGF chemotherapy (C group: case 1).

Stable disease $(\mathrm{SD})$ indicates neither sufficient shrinkage to qualify as PR nor a sufficient increase to qualify as PD in comparison to the smallest sum diameters in the study.

\section{Results}

Patient characteristics. The results from the nine sets of specimens of tumors from patients who received chemotherapy and the remaining metastatic liver tumors are shown in Table I. Patient group A (3 patients) had recurrence after primary tumor resection. This group received treatment as neoadjuvant chemotherapy. All patients $(n=6)$ in groups B and $\mathrm{C}$ received primary resection as the first treatment. $\mathrm{B}$ and C groups received 5-FU+oxaliplatin+anti-EGFR $(n=3)$ and 5FU+oxaliplatin+anti-VEGF $(n=3)$ at the liver metastasis site, respectively. All liver metastases were reduced in size (Figure 1). All 9 patients showed no signs of recurrence and were considered as good responders clinically.

Control group versus anti-VEGF therapy group. The comparison of aging-related gene expression between the control group (no chemotherapy) and the anti-VEGF therapy group revealed that in the latter the following genes: $A B C C 3, A P I S 1, A R N T, B C L 2$, BRCA2, CDK2, CDK2N2A, CDKN2D, CLPTM1L, CYP1A1, 


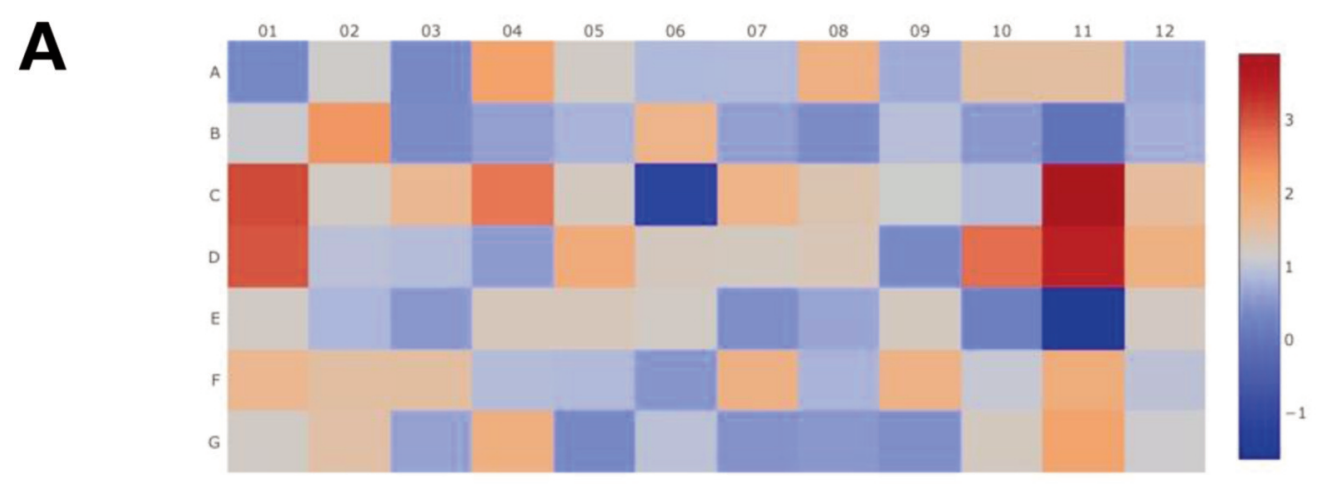

\begin{tabular}{|c|c|c|c|c|c|c|c|c|c|c|c|c|}
\hline Layout & 01 & 02 & 03 & 04 & 05 & 06 & 07 & 08 & 09 & 10 & 11 & 12 \\
\hline \multirow[t]{3}{*}{ A } & $\mathrm{ABCB} 1$ & $\mathrm{ABCC} 1$ & $A B C C 2$ & $\mathrm{ABCC} 3$ & $A B C C 5$ & $A B C G 2$ & AHR & APISI & APC & AR & ARNT & ATM \\
\hline & 1.27 & 2.22 & 1.28 & 4.43 & 2.28 & 1.80 & 1.81 & 3.64 & 1.65 & 2.87 & 2.90 & 1.59 \\
\hline & & & & & & B & & & A & B & & \\
\hline \multirow[t]{2}{*}{ B } & BAX & $\mathrm{BCL} 2$ & $\mathrm{BCL} 2 \mathrm{~L} 1$ & BLMH & BRCAI & BRCA2 & CCNDI & CCNEI & CDK2 & CDK4 & CDKNIA & CDKN1B \\
\hline & 2.11 & 5.11 & 1.31 & 1.53 & 1.74 & 3.32 & 1.52 & 1.30 & 1.90 & 1.46 & -1.03 & 1.68 \\
\hline \multirow[t]{3}{*}{$C$} & CDKN2A & CDKN2D & CLPTMIL & CYPIA1 & CYP1A2 & CYP2B6 & CYP2C19 & CYP2C8 & CYP2C9 & CYP2D6 & CYP2E1 & CYP3A4 \\
\hline & 8.51 & 2.31 & 3.15 & 6.37 & 2.35 & -2.20 & 3.39 & 2.59 & 2.18 & 1.86 & 14.93 & 2.96 \\
\hline & & & & & & & A & B & B & & A & B \\
\hline \multirow[t]{3}{*}{ D } & CYP3A5 & DHFR & EGFR & ELK1 & EPHXI & ERBB2 & ERBB3 & ERBB 4 & ERCC 3 & ESR 1 & ESR2 & FGF2 \\
\hline & 7.86 & 1.93 & 1.88 & 1.47 & 3.86 & 2.39 & 2.37 & 2.51 & 1.28 & 6.80 & 11.25 & 3.59 \\
\hline & & & & & & & & C & & & & \\
\hline \multirow[t]{2}{*}{$E$} & FOS & GSK3A & GSTPI & HIF $1 \mathrm{~A}$ & IGFIR & IGF2R & MET & $\mathrm{MSH} 2$ & MVP & MYC & NAT2 & NFKBI \\
\hline & 2.29 & 1.78 & 1.43 & 2.44 & 2.45 & 2.31 & 1.34 & 1.58 & 2.36 & 1.15 & -3.12 & 2.34 \\
\hline \multirow[t]{2}{*}{$\mathrm{F}$} & NFKB2 & NFKBIB & NFKBIE & PPARA & PPARD & PPARG & RARA & RARB & RARG & RB I & RELB & RXRA \\
\hline & 3.23 & 2.83 & 2.87 & 1.85 & 1.82 & 1.41 & 3.53 & 1.74 & 3.48 & 2.08 & 3.82 & 1.97 \\
\hline \multirow[t]{3}{*}{ G } & RXRB & SODI & SULTIEI & TNFRSFIIA & TOP1 & TOP2A & TOP2B & TP53 & TPMT & UGCG & XPA & XPC \\
\hline & 2.28 & 2.79 & 1.55 & 3.68 & 1.27 & 1.95 & 1.39 & 1.43 & 1.34 & 2.35 & 4.36 & 2.17 \\
\hline & & & B & & & & & & & & & B \\
\hline
\end{tabular}

Figure 2. Heat map and analysis matrix of control vs. VEGF therapy. Heat map (A) and analysis matrix (B) of the control group (no chemotherapy) vs. VEGF therapy group shows the expression levels of 84 aging-related genes using the Human Cancer Drug Resistance RT2 Profiler PCR array. ABCC3, BCL2, CDKN2A, CYP1A1, CYP3A5, ESR1, ESR2, and XPA were up-regulated two-fold in the VEGF-treated group.

CYP1A2, CYP2E1, CYP3A5, ERBB2, ERBB3, ESR1, ESR2, GSK3A, IGF2R, MVP, NFKB1, NFKBIE, RARA, RELB, RXRA, $R X R B, S O D 1, T P M T, U G C G$, and XPA, were significantly upregulated in comparison to the control group $(p<0.05)$. Among these genes, ABCC3, BCL2, CDKN2A, CYP1A1, CYP3A5, $E S R 1, E S R 2$, and XPA were up-regulated two-fold (Figure 2).

Control group versus anti-EGFR therapy group. Similarly, the comparison of aging-related genes between the control group (no chemotherapy) and the anti-EGFR therapy group revealed that in the latter the following genes: ABCC5, AP1S1, ATM, BRCA1, BRCA2, CDK4, CLPTM1L, ERBB3, GSK3A, HIF1A,
IGFR1, IGFR2, MSH2, MYC, MFKBIB, NFKBIE, RXRA, $T O P 2 A, T O P 2 B$, and $U G C G$, were significantly up-regulated in comparison to the control group $(p<0.05)$. Among these genes, BCL2, CY2C8,CYP2E1, CYP3A5, ERBB4, and RARA were up-regulated two-fold (Figure 3).

Anti-VEGF versus anti-EGFR therapy. The comparison of aging-related genes between the anti-VEGF and the antiEGFR therapy group revealed that ESR2 and MYC were significantly up-regulated in the former in comparison to the latter group $(p<0.05)$. Of the two genes $M Y C$ was upregulated two-fold (Figure 4 ). 
A

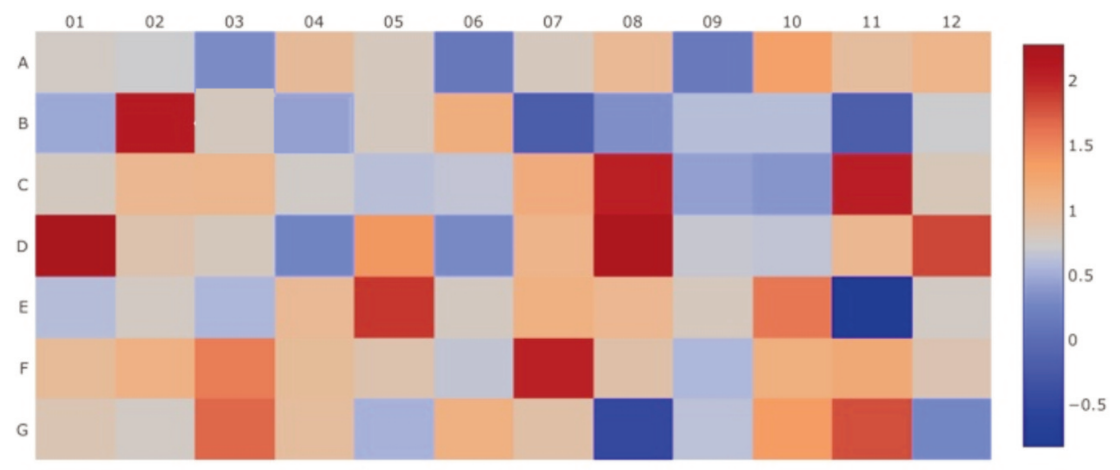

\begin{tabular}{|c|c|c|c|c|c|c|c|c|c|c|c|c|}
\hline Layout & 01 & 02 & 03 & 04 & 05 & 06 & 07 & 08 & 09 & 10 & 11 & 12 \\
\hline \multirow[t]{3}{*}{ A } & $A B C B I$ & $\mathrm{ABCCl}$ & $\mathrm{ABCC} 2$ & $\mathrm{ABCC} 3$ & $A B C C 5$ & $\mathrm{ABCG} 2$ & AHR & APISI & APC & AR & ARNT & ATM \\
\hline & 1.70 & 1.64 & 1.24 & 1.98 & 1.75 & 1.09 & 1.75 & 2.01 & 1.11 & 2.47 & 1.95 & 2.09 \\
\hline & & & & & & B & & & A & B & & \\
\hline \multirow[t]{2}{*}{ B } & BAX & $\mathrm{BCL} 2$ & BCL2LI & BLMH & BRCAI & BRCA2 & CCNDI & CCNEI & CDK2 & CDK4 & CDKNIA & CDKNIB \\
\hline & 1.39 & 4.27 & 1.73 & 1.36 & 1.74 & 2.23 & -1.15 & 1.26 & 1.53 & 1.53 & -1.14 & 1.64 \\
\hline \multirow[t]{3}{*}{ c } & CDKN2A & CDKN2D & CLPTMIL & CYPIAl & CYPIA2 & CYP2B6 & CYP2C19 & CYP2C8 & CYP2C9 & CYP2D6 & CYP2E I & CYP3A4 \\
\hline & 1.73 & 2.04 & 2.06 & 1.68 & 1.54 & 1.58 & 2.26 & 4.15 & 1.35 & 1.30 & 4.16 & 1.77 \\
\hline & A & & & B & B & & $B$ & B & B & & B & B \\
\hline \multirow[t]{3}{*}{ D } & СYР3А5 & DHFR & EGFR & ELKI & EPHXI & ERBB2 & ERBB3 & ERBB4 & ERCC3 & ESRI & ESR2 & FGF2 \\
\hline & 4.85 & 1.84 & 1.74 & 1.19 & 2.65 & 1.23 & 2.10 & 4.69 & 1.61 & 1.58 & 2.04 & 3.55 \\
\hline & & & & A & & & & $c$ & & A & B & A \\
\hline \multirow[t]{2}{*}{$\mathrm{E}$} & FOS & GSK3A & GSTP1 & HIF IA & IGFIR & IGF2R & MET & MSH2 & MVP & MYC & NAT2 & NFKB I \\
\hline & 1.52 & 1.71 & 1.48 & 2.00 & 3.77 & 1.72 & 2.18 & 2.06 & 1.75 & 2.99 & . 1.77 & 1.71 \\
\hline \multirow[t]{3}{*}{$\mathrm{F}$} & NFKB2 & NFKBIB & NFKBIE & PPARA & PPARD & PPARG & RARA & RARB & RARG & RBI & RELB & RXRA \\
\hline & 1.98 & 2.16 & 2.93 & 1.97 & 1.84 & 1.59 & 4.13 & 1.87 & 1.48 & 2.22 & 2.31 & 1.82 \\
\hline & & & & & & & & A & & & & \\
\hline \multirow[t]{3}{*}{ G } & RXRB & SODI & SULTIEI & TNFRSFIIA & TOPI & TOP2A & TOP2B & TP53 & TPMT & UGCG & XPA & XPC \\
\hline & 1.81 & 1.70 & 3.20 & 1.95 & 1.44 & 2.20 & 1.89 & -1.40 & 1.55 & 2.58 & 3.47 & 1.21 \\
\hline & & & B & A & & & & & & & & B \\
\hline
\end{tabular}

Figure 3. Heat map and analysis matrix of control vs. EGFR therapy. Heat map (A) and analysis matrix (B) of the control group (no chemotherapy) vs. EGFR therapy group shows the expression levels of 84 aging-related genes using the Human Cancer Drug Resistance RT2 Profiler PCR array. $B C L 2, C Y 2 C 8, C Y P 2 E 1, C Y P 3 A 5$, ERBB4, and RARA were up-regulated two-fold.

Overall, these data suggest that $M Y C$ transcriptional upregulation is specific to anti-EGFR therapy because it was not observed in the no-chemotherapy or anti-VEGF therapy groups. The expression of $M Y C$ may be a promising biomarker in patients receiving chemotherapy combined with anti-EGFR therapy (Figures 5-7).

\section{Discussion}

The NCCN guidelines 2018 suggested treatment for focal syndrome metastasis to the liver and lung according to tumors' surgical resectability (11). The same is true for metachronous metastases. In patients receiving i) FOLFOX/XELOX/FOLFIRI \pm bevacizumab therapy, ii) FOLFOX/FOLFIRI \pm panitumumab therapy or iii) FOLFIRI \pm cetuximab therapy (limited to all-RAS wild-type), hepatectomy is recommended for patients with unresectable liver cancer, lung focal syndrome, or those under FOLFOXIRI treatment. This stands true if it is judged that liver resection is possible after assessing the adequacy of resection every two months.

In a consensus on the definitions of resectability proposed to the European Colorectal Metastases Treatment Group by Nordlinger et al. (12), disease is categorized as i) resectable, 


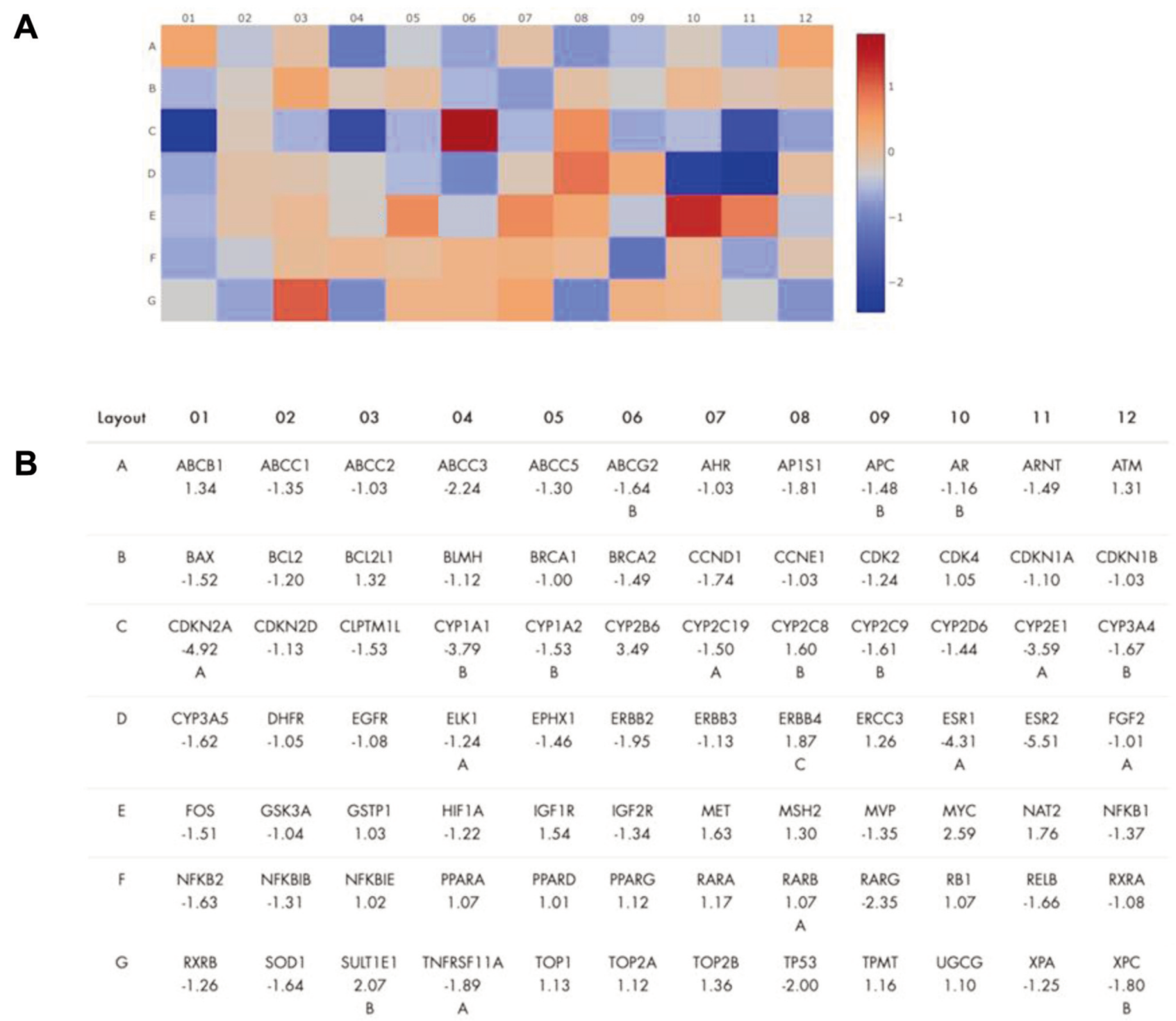

Figure 4. Heat map and analysis matrix of VEGF vs. EGF therapy. Heat map of the VEGF therapy group vs. EGFR therapy group shows the expression levels of 84 aging-related genes using the Human Cancer Drug Resistance RT2 Profiler PCR array. Only MYC was up-regulated two-fold.

ii) not optimally resectable, or iii) unresectable. Not optimally resectable is defined as "difficult to resect for technical reasons, such as proximity to hepatic vein and portal vein branches" or "technically possible to resect, but oncologically problematic, due to number of liver metastases greater than four, maximum diameter $5 \mathrm{~cm}$ or more, synchronous liver metastases, primary lymph node metastasis positive, and high levels of tumor markers." Chemotherapy in combination with molecular targeted drugs is recommended, followed by curative resection if a response is achieved (13).

It has been suggested that the angiogenesis inhibitor bevacizumab may be used in combination with chemotherapy to protect against chemotherapy-induced pathological changes in the hepatic parenchyma and to improve prognosis through pathological effects (14). According to a report by Ribero et $a l$, the onset of sinusoidal dilatation was retrospectively confirmed in 105 patients undergoing hepatectomy after combination/non-combination of bevacizumab with 5FU/oxaliplatin therapy (14). In the bevacizumab alone $27.9 \%$ cases were classified as Rubbia-Brandt Grade 2-3 compared to the $8.1 \%$ cases in the bevacizumab combined group $(p=0.006)$. In the same report, bevacizumab was reported to suppress the onset of oxaliplatin-induced sinusoidal dilation. The combination of bevacizumab was suggested to improve 


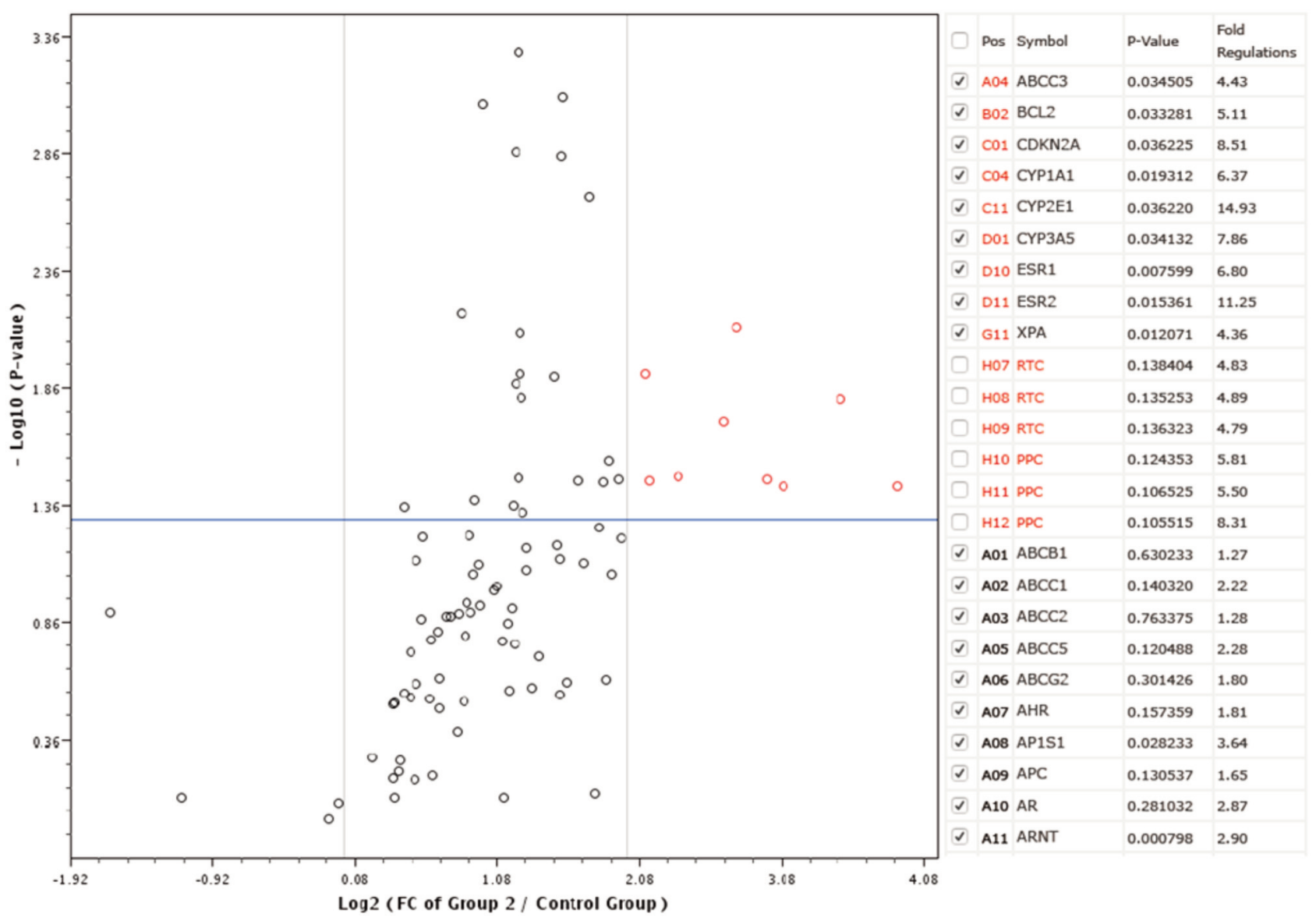

Figure 5. Gene plot of control vs. VEGF therapy. Plot of the control group (no chemotherapy) vs. VEGF therapy group shows the expression levels of 84 aging-related genes using the RT2 Profiler PCR array Human Cancer Drug Resistance. ABCC3, BCL2, CDKN2A, CYP1A1, CYP3A5, ESR1, ESR2, and XPA were up-regulated two-fold.

the tumor cell survival rate, which is an independent prognostic factor (15).

In contrast, the anti-EGFR antibody, cetuximab, in combination with chemotherapy has been reported to increase the response rate and yield a good curative hepatectomy transition rate (16). In the report by Folprecht et al., CRC liver metastasis of $\geq 5$ foci, which technically makes resection difficult, has been reported in unresectable CRC patients in a randomized Phase II clinical trial who underwent FOLFOX/FOLFIRI+cetuximab therapy as targets. Of the 106 patients, 53 who received FOLFOX+cetuximab therapy had a response rate of $68 \%$ and an R0 hepatectomy rate of $38 \%$, while in 67 cases of KRAS Exon 2 wild type, the response rate was $70 \%$ and the R0 hepatectomy rate was $33 \%$. Regarding prognosis, the median progression-free survival (PFS) time was 10.8 months in all patients. In contrast, the median overall survival in the 33 patients with KRAS Exon 2 wild type who received FOLFOX+cetuximab therapy was 33.1 months. In addition, the median PFS of 36 patients with R0 hepatectomy was 15.4 months (median recurrence-free survival after R0 hepatectomy was 9.9 months). The median overall survival was 46.7 months (16).

Therefore, the PEAK test, FIRE-3 test, and CALGB/SWOG 80405 test were performed as randomized controlled trials to compare bevacizumab and anti-EGFR antibody therapy to treat the progression of recurrent CRC (17-19). Anti-EGFR antibodies were also confirmed to have an effect on extending survival in the presence of RAS wild type. As a result of the prospective-retrospective analysis of 68 samples from these randomized controlled trials, the benefit of the anti-EGFR antibody administration could not be obtained by administering anti-VEGF antibody to which it was compared (17-19).

Recently, the multicenter, randomized phase II ATOM trial was performed to evaluate the efficacy and safety of mFOLFOX6+bevacizumab and mFOLFOX6+cetuximab in patients suffering liver-limited metastasis from wild-type allRAS CRC (20). As assessed by the independent review 


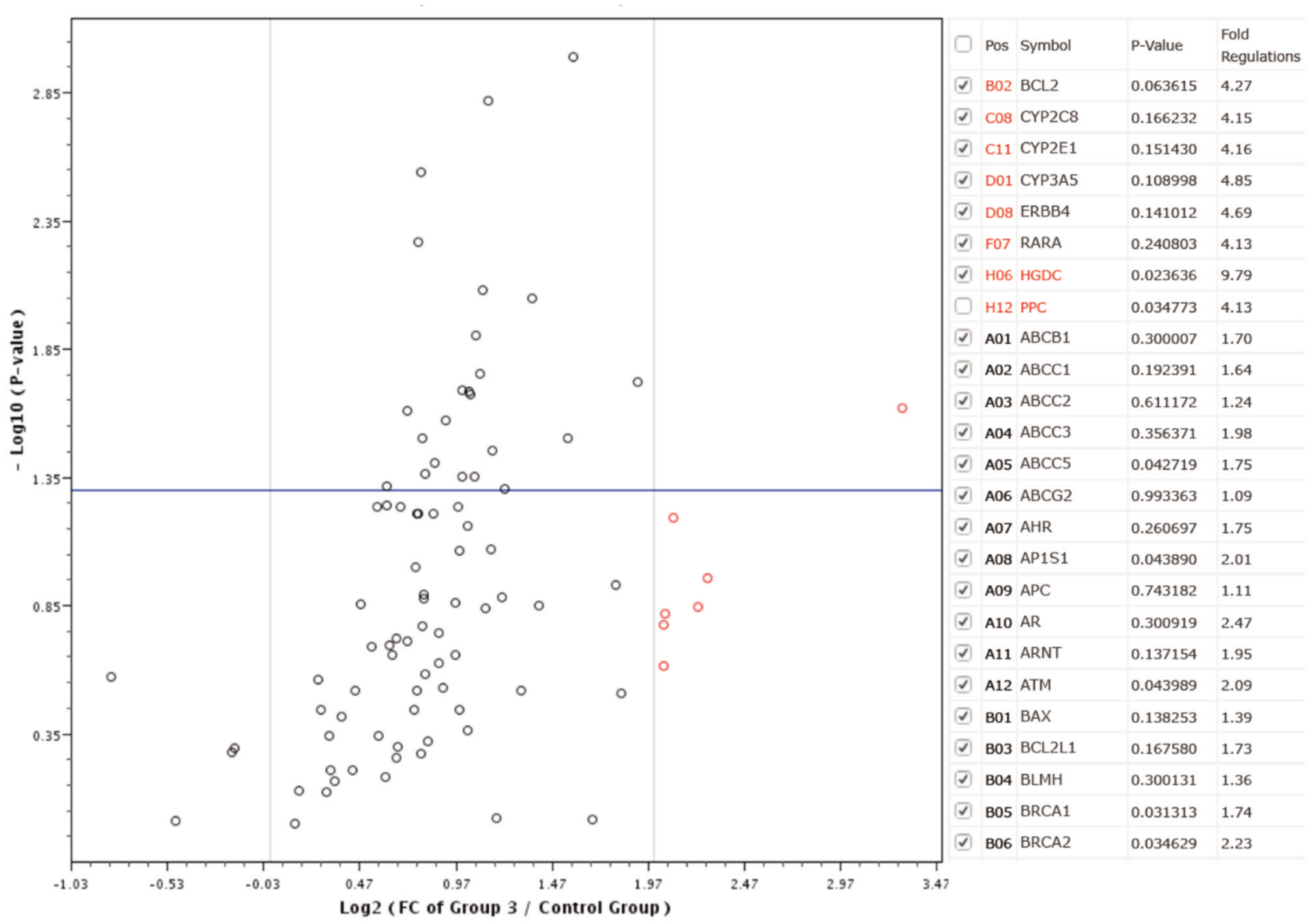

Figure 6. Gene plot of control vs. EGFR therapy. Plot of the control (no chemotherapy) vs. the anti-EGFR therapy group shows the expression levels of 84 aging-related genes using the RT2 Profiler PCR array Human Cancer Drug Resistance. BCL2, CY2C8, CYP2E1, CYP3A5, ERBB4, and RARA were up-regulated two-fold.

committee, the median PFS for the cetuximab arm was 14.8 months [95\% confidence interval $(\mathrm{CI})=9.7-17.3$ months], whereas that for the bevacizumab arm was 11.5 months (95\% CI=9.2-13.3 months; log-rank $p=0.33$ ). The hazard ratio (HR) was 0.803 (95\% $\mathrm{CI}=0.513-1.256)$ for $\mathrm{PFS}$ between the two arms. Median overall survival in the bevacizumab arm was 30.4 months, in the cetuximab arm it was not achieved $(\mathrm{HR}=0.827,95 \% \mathrm{CI}=0.437-1.564)$. The median tumor shrinkage rate at 8 weeks was $25.3 \%$ in the bevacizumab arm vs. $37.8 \%$ in the cetuximab arm. During follow up of patients treated by surgical resection of tumors with R0/R1 status, the median PFS of the bevacizumabtreated group was 6.5 months $(95 \% \mathrm{CI}=4.0-13.6)$, whereas in the cetuximab arm it was 13.8 months $(95 \% \mathrm{CI}=8.4-$ not reached $), \mathrm{HR}=0.610(95 \% \mathrm{CI}=0.298-1.245)$. Of the 57 tumors for which the histopathological analysis was assessable, the Grade 1b/2/3 histopathological response rate was $66.6 \%(20 / 30)$ in the bevacizumab arm and $92.6 \%$ $(25 / 27)$ in the cetuximab arm $(p=0.0229)(20)$.
When considering a multidisciplinary treatment strategy for liver-localized CRC (KRAS exon 2 wild type or RAS wild type) that is difficult to curatively resect at the time of the initial diagnosis, anti-VEGF antibody and anti-EGFR antibody can be used as molecular targeted drugs in combination with chemotherapy. As there is no clear evidence as to which anti-EGFR antibody drug is suitable in every case, the evidence from this study is highly valuable.

In the present study the expression of genes associated with drug resistance was evaluated with a pathway expression analysis using the RT2 Profiler PCR Array, and comparison of gene expression in primary $\mathrm{CRC}$ and residual metastatic liver tumors following treatment with either antiEGFR or anti-VEGF therapies was performed. Previously, in patients who had received anti-EGFR treatment with chemotherapy, MYC expression in metastatic liver tumors was stronger compared to patients who had received antiVEGF treatment with chemotherapy (21). 


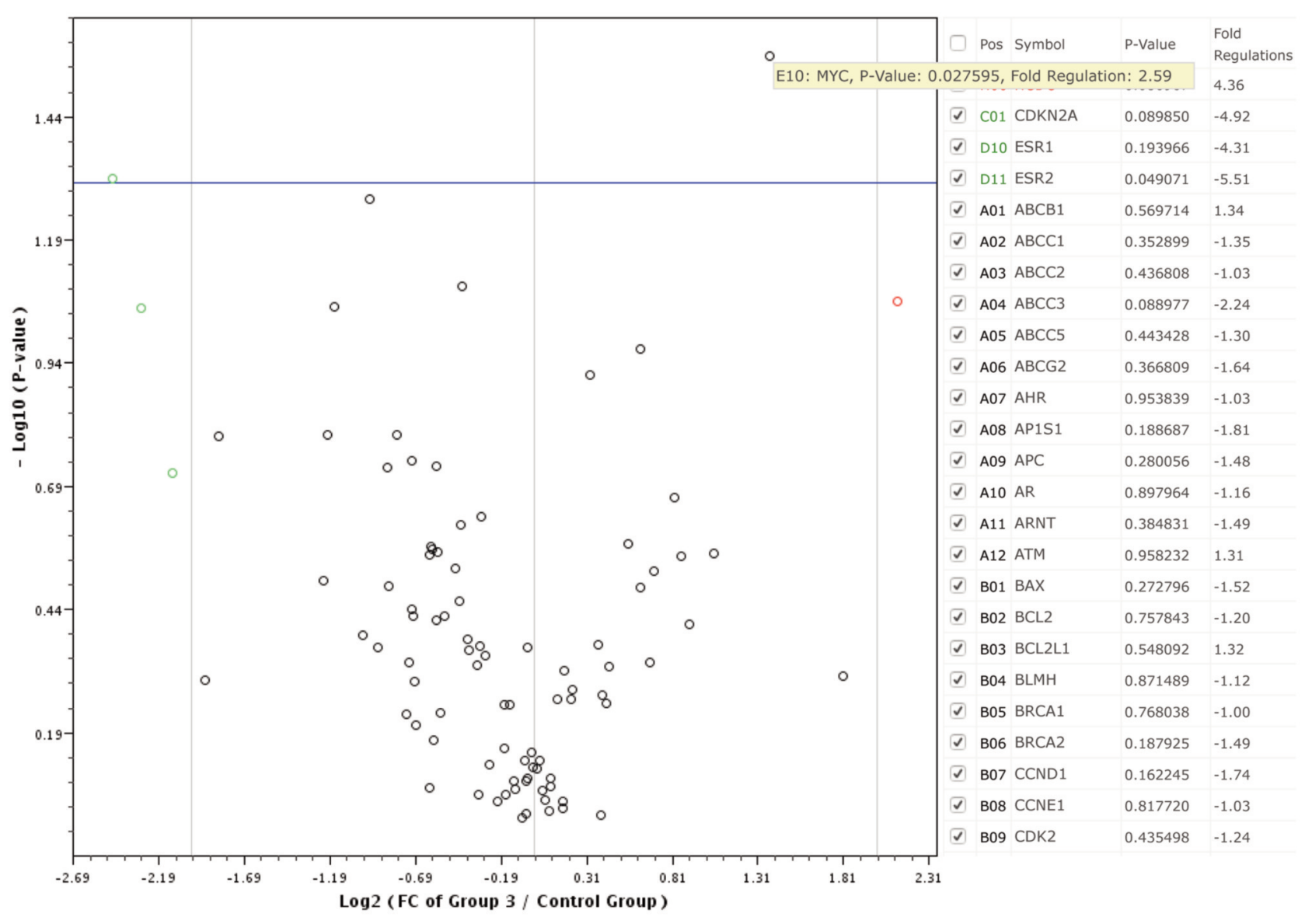

Figure 7. Gene plot of VEGFR vs. EGFR therapy. Plot of the VEGF therapy vs. the EGFR therapy group shows the expression levels of 84 agingrelated genes using the RT2 Profiler PCR array Human Cancer Drug Resistance. Only MYC was up-regulated two-fold.

The MYC transcription factor is central to cellular growth control, cell transformation and tumorigenesis. Under homeostasis, MYC expression generally occurs in cells with a regenerative and proliferative potential. However, its overexpression directly affects malignant transformation in various cell types and is a notable characteristic in many human cancers (22). MYC regulation occurs at both the transcriptional and post-transcriptional levels and is a direct target and effector of growth-regulatory cascades, such as the EGFR pathway (23).

Bonamy et al. have reported that the MEKK1/2-ERK1/2 signaling cascade, the ultimate controller of MYC transcription factor gene expression, mediates the EGFR-dependent regulation of the human $\beta$-defensin-1 (HBD1) (24). HBD1 is an antimicrobial peptide constitutively expressed by epithelial cells at mucosal surfaces. In addition to its microbicidal properties, the loss of HBD1 expression in several cancers suggests that it may also have an anti-tumor activity (25).

The same group have also noted that the regulatory circuit of the EGFR-MEKK1/2-ERK1/2-MYC axis, which is dysregulated in many types of human cancers, is involved in controlling the constitutive expression of HBD1. Thus, MYC increases along with $\mathrm{p} 53$, which results in cell cycle entry and p53-dependent apoptosis (26). We hypothesized that MYC transcription may be increased in tumor specimens obtained from CRC patients and that the MEKK1/2-ERK1/2 signaling cascade may be the main pathway transducing the signal from EGFR to MYC.

Various roles are reported for MYC that include essential cofactor interactions, targeting activity, inhibition of kinasedependent activation, targeting of druggable key downstream target gene products, and exploiting synthetic lethal interactions. On the basis of the results of the present study, we expect to be able to target MYC directly or indirectly in the future.

In conclusion, after recent updates in the clinical guidelines from Japan, the US and EU, the genomic evaluation of KRAS, NRAS, BRAF, and MSI has become essential in planning cancer treatment. However, large full-gene sequencing projects have identified additional mutations other than these hotspots. Patients who receive anti-EGFR with 
chemotherapy may develop tumors with superior pathway activity, such as tumors treated with oxaliplatin) in comparison to those who receive anti-VEGF therapy with chemotherapy (27). In the future, it is predicted that the $M Y C$ gene will be found to be involved in CRC liver metastasis, which may affect the use of molecular targeted drugs.

\section{Conflicts of Interest}

KY has received honoraria for lectures from Chugai Pharmaceutical Co., Ltd., Taiho Pharmaceutical Co., Ltd., Takeda Pharmaceutical Co., Ltd., Eli Lilly and Company, Daiichi Sankyo Co., Ltd., Ono Pharmaceutical Co., Ltd., Merck Serono Co., Ltd., Novartis Pharma K.K., and Sanofi K.K.; and research funding from Ajinomoto Pharmaceutical Co., Ltd., Takeda Pharmaceutical Co., Ltd., Chugai Pharmaceutical Co., Ltd., Daiichi Sankyo Co., Ltd., Taiho Pharmaceutical Co., Ono Pharmaceutical Co., and Yakult Honsha Co., Ltd. outside the submitted work.

TT has received honoraria for lectures from Takeda Pharmaceutical Co., Ltd. All remaining Authors declare that they have no conflicts of interest.

\section{Authors' Contributions}

TK, NM, and HT conceived the study and its design. TK, NM, HT, TT, YI, MF, IY, TS, TI, RM, HI, YT, NO, AH, and KYo acquired the data. TK, NM, and HT analyzed and interpreted the data and drafted the manuscript. NM, TT, and KYo performed critical revision of the manuscript. AH and KYo supervised the study. All Authors read and approved the final manuscript.

\section{References}

1 Bray F, Ferlay J, Soerjomataram I, Siegel RL, Torre LA and Jemal A: Global cancer statistics 2018: GLOBOCAN estimates of incidence and mortality worldwide for 36 cancers in 185 countries. CA Cancer J Clin 68(6): 394-424, 2018. PMID: 30207593. DOI: $10.3322 /$ caac. 21492

2 Cancer Statistics in Japan 2018. Available at: https:// ganjoho.jp/reg_stat/statistics/brochure/backnumber/2018_jp.html

3 NCCN guidelines for patients 2018. Available at: https:// www.nccn.org/patients/guidelines/content/PDF/colon-patient.pdf

4 Saltz LB, Clarke S, Díaz-Rubio E, Scheithauer W, Figer A, Wong R, Koski S, Lichinitser M, Yang TS, Rivera F, Couture F, Sirzén $\mathrm{F}$ and Cassidy J: Bevacizumab in combination with oxaliplatin-based chemotherapy as first-line therapy in metastatic colorectal cancer: a randomized phase III study. J Clin Oncol 26(12): 2013-2019, 2008. PMID: 18421054. DOI: 10.1200/ JCO.2007.14.9930

5 Van Cutsem E, Köhne CH, Hitre E, Zaluski J, Chang Chien CR, Makhson A, D’Haens G, Pintér T, Lim R, Bodoky G, Roh JK, Folprecht G, Ruff P, Stroh C, Tejpar S, Schlichting M, Nippgen J and Rougier P: Cetuximab and chemotherapy as initial treatment for metastatic colorectal cancer. N Engl J Med 360(14): 1408-1417, 2009. PMID: 19339720. DOI: 10.1056/NEJMoa0805019

6 Ciardiello $\mathrm{F}$ and Tortora G: EGFR antagonists in cancer treatment. N Engl J Med 358: 1160-1174. 2008.PMID: 18337605. DOI: $10.1056 /$ NEJMra0707704
7 Feng QY, Wei Y, Chen JW, Chang WJ, Ye LC, Zhu DX and Xu JM: Anti-EGFR and anti-VEGF agents: important targeted therapies of colorectal liver metastases. World J Gastroenterol 20(15): 4263-4275, 2014. PMID: 24764664. DOI: $10.3748 /$ wjg.v20.i15.4263

8 Bokemeyer C, Bondarenko I, Makhson A, Hartmann JT, Aparicio J, de Braud F, Donea S, Ludwig H, Schuch G, Stroh C, Loos AH, Zubel A and Koralewski P: Fluorouracil, leucovorin, and oxaliplatin with and without cetuximab in the first-line treatment of metastatic colorectal cancer. J Clin Oncol 27(5): 663-671, 2009. PMID: 19114683. DOI: 10.1200/JCO.2008.20.8397

9 Saltz LB, Clarke S, Díaz-Rubio E, Scheithauer W, Figer A, Wong R, Koski S, Lichinitser M, Yang TS, Rivera F, Couture F, Sirzén $\mathrm{F}$ and Cassidy J: Bevacizumab in combination with oxaliplatin-based chemotherapy as first-line therapy in metastatic colorectal cancer: A randomized phase III study. J Clin Oncol 26(12): 2013-2019, 2008. PMID: 18421054. DOI: 10.1200/ JCO.2007.14.9930

10 Macedo LT, da Costa Lima AB and Sasse AD: Addition of bevacizumab to first-line chemotherapy in advanced colorectal cancer: a systematic review and meta-analysis, with emphasis on chemotherapy subgroups. BMC Cancer 89: 12, 2012. PMID: 22414244. DOI: $10.1186 / 1471-2407-12-89$

11 Benson AB, Venook AP, Al-Hawary MM, Cederquist L, Chen YJ, Ciombor KK, Cohen S, Cooper HS, Deming D, Engstrom PF, Garrido-Laguna I, Grem JL, Grothey A, Hochster HS, Hoffe S, Hunt S, Kamel A, Kirilcuk N, Krishnamurthi S, Messersmith WA, Meyerhardt J, Miller ED, Mulcahy MF, Murphy JD, Nurkin S, Saltz L, Sharma S, Shibata D, Skibber JM, Sofocleous CT, Stoffel EM, Stotsky-Himelfarb E, Willett CG, Wuthrick E, Gregory KM and Freedman-Cass DA: NCCN Guidelines Insights: Colon Cancer, Version 2.2018. Natl Compr Canc Netw 16(4): 359-369, 2018. PMID: 29632055. DOI: 10.6004/ jncen.2018.0021

12 Nordlinger B, Van Cutsem E, Gruenberger T, Glimelius B, Poston G, Rougier P, Sobrero A and Ychou M: Combination of surgery and chemotherapy and the role of targeted agents in the treatment of patients with colorectal liver metastases: recommendations from an expert panel. Ann Oncol 20(6): 985992, 2009. PMID: 19153115. DOI: 10.1093/annonc/mdn735

13 Nordlinger B, Van Cutsem E, Rougier P, Köhne CH, Ychou M, Sobrero A, Adam R, Arvidsson D, Carrato A, Georgoulias V, Giuliante F, Glimelius B, Golling M, Gruenberger T, Tabernero J, Wasan H and Poston G; European Colorectal Metastases Treatment Group: Does chemotherapy prior to liver resection increase the potential for cure in patients with metastatic colorectal cancer? A report from the European Colorectal Metastases Treatment Group. Eur J Cancer 43(14): 2037-2045, 2007. PMID: 17766104. DOI: 10.1016/j.ejca.2007.07.017

14 Ribero D, Wang H, Donadon M, Zorzi D, Thomas MB, Eng C, Chang DZ, Curley SA, Abdalla EK, Ellis LM and Vauthey JN: Bevacizumab improves pathologic response and protects against hepatic injury in patients treated with oxaliplatin-based chemotherapy for colorectal liver metastases. Cancer 110(12): 2761-2767, 2007. PMID: 17960603. DOI: 10.1002/cncr.23099

15 Marino D, Leone F, D'Avanzo F, Ribero D, Capussotti L and Aglietta M: Potentially resectable metastatic colorectal cancer: an individualized approach to conversion therapy. Crit Rev Oncol Hematol 92(3): 218-226, 2014. PMID: 24985058. DOI: $10.1016 /$ j.critrevonc. 2014.05 .010 
16 Folprecht G, Gruenberger T, Bechstein WO, Raab HR, Lordick F, Hartmann JT, Lang H, Frilling A, Stoehlmacher J, Weitz J, Konopke R, Stroszczynski C, Liersch T, Ockert D, Herrmann T, Goekkurt E, Parisi F and Köhne CH: Tumour response and secondary resectability of colorectal liver metastases following neoadjuvant chemotherapy with cetuximab: the CELIM randomised phase 2 trial. Lancet Oncol 11(1): 38-47, 2010. PMID: 19942479. DOI: 10.1016/S1470-2045(09)70330-4

17 Rivera F, Karthaus M, Hecht JR, Sevilla I, Forget F, Fasola G, Canon JL, Guan X, Demonty G and Schwartzberg LS: Final analysis of the randomised PEAK trial: overall survival and tumour responses during first-line treatment with mFOLFOX6 plus either panitumumab or bevacizumab in patients with metastatic colorectal carcinoma. Int J Colorectal Dis 32(8): 1179-1190, 2017. PMID: 28424871. DOI: 10.1007/s00384-0172800-1

18 Heinemann V, von Weikersthal LF, Decker T, Kiani A, VehlingKaiser U, Al-Batran SE, Heintges T, Lerchenmüller C, Kahl C, Seipelt G, Kullmann F, Stauch M, Scheithauer W, Hielscher J, Scholz M, Müller S, Link H, Niederle N, Rost A, Höffkes HG, Moehler M, Lindig RU, Modest DP, Rossius L, Kirchner T, Jung A and Stintzing S: FOLFIRI plus cetuximab versus FOLFIRI plus bevacizumab as first-line treatment for patients with metastatic colorectal cancer (FIRE-3): a randomised, open-label, phase 3 trial. Lancet Oncol 15(10): 1065-1075, 2014. PMID: 25088940. DOI: $10.1016 / \mathrm{S} 1470-2045(14) 70330-4$

19 Elez E, Argilés G and Tabernero J: First-Line Treatment of Metastatic Colorectal Cancer: Interpreting FIRE-3, PEAK, and CALGB/SWOG 80405. Curr Treat Options Oncol 16(11): 52, 2015. PMID: 26374340. DOI: 10.1007/s11864-015-0369-x

20 Oki E, Emi Y, Yamanaka T, Uetake H, Muro K, Takahashi T, Nagasaka T, Hatano E, Ojima H, Manaka D, Kusumoto T, Katayose Y, Fujiwara T, Yoshida K, Unno M, Hyodo I, Tomita N, Sugihara K and Maehara Y: Randomised phase II trial of mFOLFOX6 plus bevacizumab versus mFOLFOX6 plus cetuximab as first-line treatment for colorectal liver metastasis (ATOM trial). Br J Cancer 121(3): 222-229, 2019. PMID: 31285591.DOI: 10.1038/s41416-019-0518-2

21 Stine ZE, Walton ZE, Altman BJ, Hsieh Al and Dang CV: MYC, Metabolism, and Cancer. Cancer Discov 5(10): 1024-1039, 2015. PMID: 26382145. DOI: 10.1158/2159-8290.CD-15-0507

22 Marcu KB, Bossone SA and Patel AJ: Myc function and regulation. Annu Rev Biochem 61: 809-860, 1992. PMID: 1497324. DOI: 10.1146/annurev.bi.61.070192.004113

23 McCray PB and Bentley L: Human airway epithelia express a beta-defensin. Am J Respir Cell Mol Biol 16(3): 343-349, 1997. PMID: 9070620. DOI: 10.1165/ajrcmb.16.3.9070620

24 Castell A and Larsson LG: Targeting MYC Translation in Colorectal Cancer. Cancer Discov 5(7): 701-703, 2015. PMID: 26152922. DOI: 10.1158/2159-8290.CD-15-0660

25 Bonamy C, Sechet E, Amiot A, Alam A, Mourez M, Fraisse L, Sansonetti PJ and Sperandio B: Expression of the human antimicrobial peptide $\beta$-defensin- 1 is repressed by the EGFRERK-MYC axis in colonic epithelial cells. Sci Rep 8(1): 18043, 2018. PMID: 30575780. DOI: 10.1038/s41598-018-36387-z

26 Kress TR, Sabò A and Amati B: MYC: connecting selective transcriptional control to global RNA production. Nat Rev Cancer 15: 593-607, 2015. PMID: 26383138. DOI: 10.1038/ nrc3984

27 Nakamura Y and Yoshino T: Clinical utility of analyzing circulating tumor DNA in patients with metastatic colorectal cancer. Oncologist 23: 1310-1318, 2018. PMID: 29700206. DOI: 10.1634/theoncologist.2017-0621
Received September 5, 2020

Revised October 2, 2020

Accepted October 15, 2020 